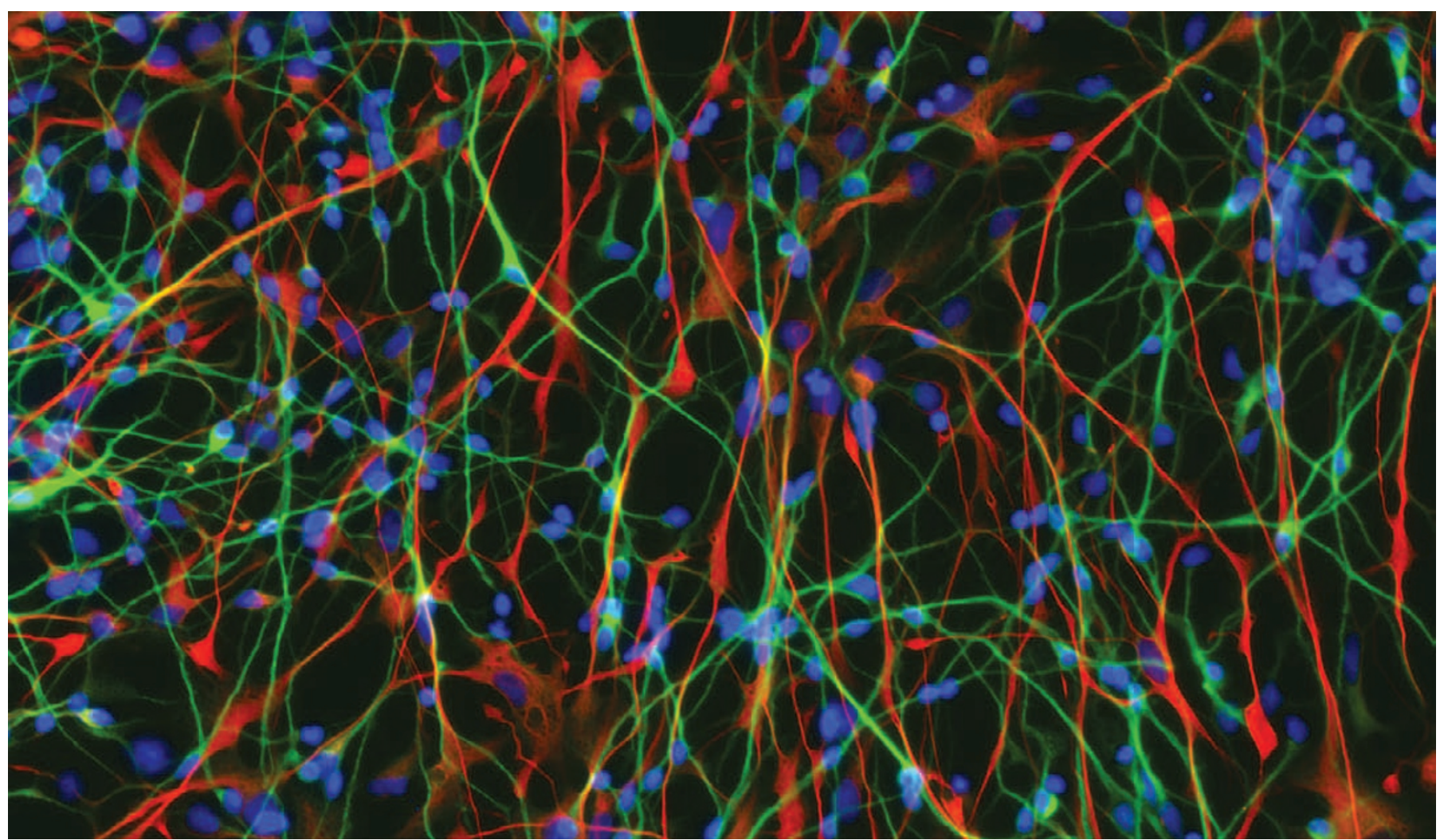

Researchers are mutating autism-associated genes in brain cells in cell culture to see how the cellular biochemistry is altered.

\title{
Searching for answers
}

\section{Solving the riddle of autism genetics will require looking beyond the growing list of candidate genes to epigenetics and personalized medicine.}

\section{BY SARAH C. P. WILLIAMS}

A t Rutgers University in New Brunswick, New Jersey, blood samples from 3,000 people with autism and their families have been carefully collected and tested over the past five years. The DNA from each of the samples - almost 13,000 in total - has been extracted, studied and shared with researchers around the world. And each person with autism whose genes are in the collection has been put through batteries of tests and examinations to characterize their condition. The Simons Simplex Collection, as the set of data is known, is one of the largest - and most comprehensive - of the handful of autism cohorts around the world. But even so, it hasn't given up many of autism's secrets.

Each new study using the Simons data - or one of the other similar collections - adds to a growing list of gene variations that could relate to the disorder, or perhaps even be the cause in some cases. But on the whole, the expanding catalogue of genes doesn't explain what causes autism at a cellular or molecular level, what characteristics the mutations share, or how to treat the disorder. For researchers, autism is a riddle that is ever more complex. And for patients and their families, it's a story of how science can lead to discovery after discovery but be slow to improve treatments and change lives. Now, however, a new research strategy that integrates protein and epigenetic studies into classic genetic screens might reveal some of the disease's causes and potentially lead to successful, targeted treatments.

\section{THE ROLE OF GENETICS}

"From a genetics standpoint, it's been clear for a while now that there isn't going to be an autism gene," says Daniel Geschwind, a neurologist and autism researcher at the University of California, Los Angeles. "But the idea now is that we're moving from just looking under the proverbial street light to integrating many different approaches to solve this problem."

The latest estimates by the US Centers for Disease Control and Prevention state that 1 in 88 children in the United States has been identified with an autism spectrum disorder. Symptoms range from mild social impairment to severe developmental delays and challenges in language, communication, social interaction and behaviour. It's been known for

"There is just not enough postmortem tissue that fits our criteria."

\section{autism, the other has}

the disorder almost 100 per cent of the time ${ }^{1}$. More recent studies have found slightly lower numbers in twin and sibling studies, but they still estimate that well over half of all autism cases can be attributed to genetic, rather than environmental, factors ${ }^{2}$.

And there's another piece of evidence for inheritance: it's become increasingly clear that 
older parents - fathers in particular - are at increased risk of conceiving children with autism. A study published in August 2012 found that for every increasing year of a father's age, from 20 to 65 years, the number of mutations passed along to his offspring increased ${ }^{3}$. The research suggests that a man's genetic material accumulates mistakes over his lifetime, as sperm cells are continuously copied. But which of these genetic mutations lead to autism?

\section{SEARCHING THE GENOME}

Many of the early studies hunting for autism genes were genome-wide association studies (GWAS). Such studies compare the DNA of people with and without a disorder using thousands or millions of markers scattered throughout their genomes. However, GWAS can only point to large chromosome regions rather than identifying particular genes or gene mutations. The first GWAS on autism, published in 2009, implicated two regions with mild effects: one on chromosome 5, and one on chromosome 20 (ref. 4). Subsequent GWAS on autism have failed to turn up any other parts of the genome with statistical significance. Many researchers were disappointed by these results, which suggested that the common genetic variants that GWAS detects explain only a small fraction of the symptoms of autism. "The commonvariant hypothesis was essentially tested," says

Geschwind. "And it doesn't mean that common variants don't contribute at all, but they have small effects. So let's look at the rare variants."

But at the University of Southern California in Los Angeles, neurogeneticist Dan Campbell wanted to be sure that all the information possible was culled from the GWAS data before he moved on. "Our approach has been to go back to those genome-wide signals," says Campbell. He was convinced that common variants played some role in autism because of studies that had found broad autistic traits in up to half of all children with autism.

So Campbell's lab started studying, in more depth than ever before, the two regions that had been located. They've already found a gene on chromosome 5 that could play a role. The surprise, and the reason it hadn't been identified earlier, is that it's a non-coding RNA. Instead of being the basis for a protein, the gene is translated into an RNA molecule that has activity in the cell in its own right. In this case, the RNA binds to a different gene - one that makes a protein called moesin, which is known to be involved in brain development. The non-coding RNA turns off the moesin gene, which is critical to early brain development. Without moesin, the neuronal projections (axons and dendrites) are shorter than normal. Brain samples from deceased autism patients, Campbell's team reported in April 2012, have on average 12 times more of the non-coding RNA than usual, suggesting that levels of moesin might have been stunted at some time during development ${ }^{5}$. More work is needed to test whether the altered moesin levels lead to altered brain morphology in people with autism.

Like all the findings on genes implicated in autism, this non-coding RNA doesn't explain all instances of the condition. And even in people who have the common variant and display an increase in these RNA levels, it might not be the full story. "Some cases of autism you can nail down to, 'there's a mutation in this gene," says Campbell. "Some cases will be due to people inheriting a common genetic variant." And other cases, he said, could be the result of a combination of common genetic variants with an uncommon gene variant or an environmental factor.

With the dropping price of genetic sequencing, many researchers have moved from GWAS to more in-depth sequencing of DNA from people with autism and their unaffected family members in an effort to unearth rarer mutations. In April 2012, three research papers reported the sequencing of exomes (the encoding portions of the genome) from a combined

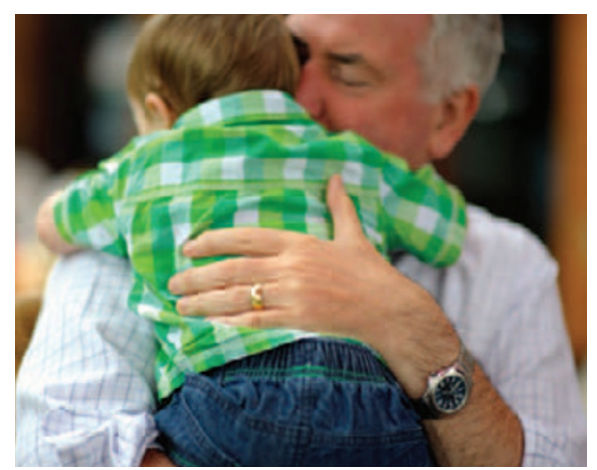

Children born of older fathers are more likely to have autism.

total of more than 1,000 autism patients and hundreds of family members. Together, the studies turned up in excess of 1,000 genes from across the genome associated with autism, far surpassing previous estimates of how many rare genes could contribute to the disorder.

The challenge, says geneticist Jay Shendure of the University of Washington in Seattle, is that the rarer a mutation is, the larger the sample size required to prove its association with autism. There are hundreds of thousands of people with autism spectrum disorder in the United States, for example, but only a tiny fraction of that population is part of any wellcharacterized study like the Simons Simplex Collection. "The cost of sequencing is dropping at such an incredible rate that I do think there will come a time in the next few years when all the good cohorts out there have been sequenced," says Shendure. "But the sample sizes to implicate these genes may need to be much larger, and that means we need more cohorts." The number of people with autism in the United States is large, but it takes time to enrol patients in studies - each person must have in-depth, standardized testing.
Finding the genetic variations is one mission; understanding what they mean is another. Shendure says that new analytical techniques are needed to put the growing list of autism genes into context. By using maps of protein-protein interactions throughout cells, for example, researchers can find networks of proteins affected by many different genetic mutations, suggesting a common mechanism for disease. Or, by relying on new catalogues of gene expression data, they can pin down which cells might be influenced by known mutations. "The more sorts of data we have to intersect our data with, the more we can get out of it," says Shendure.

\section{MOVING BEYOND GENES}

The systems biology approach that Shendure proposes is one that Geschwind also endorses. The rare mutations that turn up in exome studies are not necessarily all causative of autism. So using data from the Simons Simplex Collection, Geschwind and colleagues recently profiled the transcriptomes (the set of all RNAs produced) of 244 people with autism and members of their family to get a sense of which genetic mutations led to real changes in gene expression. "Pathway convergence is likely to be quite important," says Geschwind. "You can imagine that many distinct genes could end up leading to a similar circuit-level dysfunction in the brain."

Geschwind's study found that many of these genes with altered expression patterns were clustered in pathways known to play important roles in neuron function, development and structure ${ }^{6}$. This discovery suggests common mechanisms through which seemingly different gene mutations could cause disease. Treatments targeting those pathways might help many patients who have different gene mutations playing into the same networks.

Geschwind's team analysed gene expression patterns in the brains of 19 people with autism and 17 without, using brain tissue collected after each person's death ${ }^{7}$. For each brain, the scientists studied three different regions, all thought to be important in autism. They found that in people with autism, two regions of the brain that normally have distinct patterns of gene expression - the frontal and temporal lobes of the cerebral cortex - instead had almost identical patterns, with the same genes switched on or off. The altered genetics suggest a lack of specialization among some brain cells, which could lead to differences in how the brain processes information.

Geschwind's brain study was small. “There is just not a lot of post-mortem tissue that fits our criteria," he says. "So you are stuck with small cohorts." As tissue collections grow in the future, he hopes to repeat the studies and explore more of the unique brain morphology associated with autism.

At the University of California, Davis, genetics and immunology researcher Janine LaSalle is also looking beyond straightforward genetic 


\begin{tabular}{|c|c|c|c|}
\hline \multicolumn{4}{|c|}{$\begin{array}{l}\text { A CATALOGUE OF CANDIDATES } \\
\text { A sample of genetic suspects that may be responsible for causing autism }\end{array}$} \\
\hline Gene & Chromosome & $\begin{array}{l}\text { Studies that have } \\
\text { linked autism to } \\
\text { genetic factors }\end{array}$ & Description \\
\hline CACNA1H & 16 & 11 & $\begin{array}{l}\text { Mutations in this calcium channel could change the } \\
\text { way neurons function or the way the brain develops. }\end{array}$ \\
\hline CNTNAP2 & 7 & 20 & $\begin{array}{l}\text { This gene's protein associates with potassium } \\
\text { channels on neurons and may play a role in the } \\
\text { differentiation of a nerve cell's axons. }\end{array}$ \\
\hline CNTN4 & 3 & 9 & $\begin{array}{l}\text { Encodes a membrane protein that helps axons form } \\
\text { in the developing nervous system. }\end{array}$ \\
\hline FOXP2 & 7 & 16 & $\begin{array}{l}\text { Encodes a protein that regulates other genes, } \\
\text { including CNTNAP2. Studies have shown that it is } \\
\text { important to neural plasticity. }\end{array}$ \\
\hline MECP2 & $\mathrm{X}$ chromosome & 26 & $\begin{array}{l}\text { The MECP } 2 \text { protein is implicated in Rett syndrome } \\
\text { and known to be involved in turning off other genes } \\
\text { in nerve cells. }\end{array}$ \\
\hline MET & 7 & 21 & $\begin{array}{l}\text { Best known as a proto-oncogene, but signalling by } \\
M E T \text { has also been linked to the development of } \\
\text { certain parts of the brain. }\end{array}$ \\
\hline NRXN1 & 2 & 28 & $\begin{array}{l}\text { Encodes membrane proteins active at the synapse } \\
\text { between two neurons. }\end{array}$ \\
\hline OTXR & 3 & 20 & $\begin{array}{l}\text { The OTXR protein helps control the levels in the } \\
\text { brain of the neurotransmitter oxytocin. }\end{array}$ \\
\hline RAl1 & 17 & 7 & $\begin{array}{l}\text { Mutations in RAl1 are associated with certain } \\
\text { syndromic causes of autism. }\end{array}$ \\
\hline SHANK3 & 22 & 19 & $\begin{array}{l}\text { Involved in the development of synapses between } \\
\text { neurons. Mice lacking Shank3 show symptoms. }\end{array}$ \\
\hline
\end{tabular}

screens for autism variants, in the hope that she will tie together the hundreds of autism genes being discovered with a finding on another level. Instead of focusing on proteins, LaSalle is looking at epigenetics - changes to gene expression through chemical and structural modifications to DNA, such as the addition of a methyl group to DNA, rather than changes to the code itself.

Epigenetic patterns in cells can be passed from parent to child or influenced by the environment, and can cause major changes to molecular pathways. If epigenetic alterations were discovered in people with autism, they could go so far as to explain the complexity of the disorder, says LaSalle. "Even a subtle hit to one of these pathways through changes in methylation could have the same impact as knocking out an entire gene," she says.

Already, Rett syndrome, an autism spectrum disorder, is providing hints. This neurodevelopmental disorder, which primarily affects females, leads to physical abnormalities as well as repetitive motions and a lack of verbal skills. The syndrome has been linked to a gene, $M E C P 2$, that controls the epigenetic silencing of other genes in neurons. LaSalle has shown that in mice, mutations in $M E C P 2$ change the way genes are turned on and off in response to a chemical found in flame retardants. Her results don't prove that these chemicals are a cause of autism, but they suggest that MECP2's epigenetic mechanisms could link genetic and environmental impacts in autism ${ }^{8}$. Researchers in the emerging field of environmental epigenetics have already found that many

environmental toxins and pollutants reduce overall methylation in cells, she says.

But epigenetics is a young field and new techniques are needed to be able to fully understand how methylation is controlled and, in particular, how it might have unique roles in neurons. There's evidence that in neurons, methylation is influenced not only by environmental and inherited factors, but also by neuronal activity itself, setting up a feedback loop. Moreover, neurons have been found to show different epi-
"I see cancer as being about a decade ahead of neuroscience." genetic patterns to the rest of the body ${ }^{9}$. Until recently, it was thought that most methylation was concentrated in the

promoters of genes, so most commercial tests for methylation are biased toward promoters. As the technology for studying these patterns improves, LaSalle says, additional epigenetic associations with autism will emerge. For example, epigenetic modifications could influence the same genes and pathways that genetic mutations alter. "The real key is overlaying the epigenetic data with data from genome-wide association studies and having people work together," says LaSalle.

\section{OPTIMISTIC HUNTERS}

So far, no single gene has been discovered that accounts for more than a few per cent of autism cases. Still, the discovery over the past decade of more than 100 autism-related genes is progress of a sort. Indeed, according to Geschwind, known diseases and mutations now collectively explain almost one-fifth of autism cases. "If you asked me 10 years ago if I thought we'd be on the threshold of understanding some genetic risk in $20-25 \%$ of autism, I would have thought that would be very, very optimistic," he says. "But the field has moved rapidly."

Most recently, a potential treatment for a rare form of autism that involves a mutation in the $B C K D K$ gene was reported ${ }^{10}$. Experiments with $B C K D K$-deficient mice showed improvement when administered diets rich with branched-chain amino acids (BCAA) $B C K D K$ mutations diminish BCAA levels, and in human patients the regimen helped restore plasma BCAA levels. These are promising developments that could lead to treatment by sequencing exomes in order to link specific genes to their physiological effects.

Eventually, Geschwind says, treatments for autism may become personalized. Genetic tests could determine which treatments would work in a certain patient's case. But first, studies on broader protein networks and the underlying causes of autism are likely to lead to more general treatments that work for at least some patients, although as these treatments will target broad cellular pathways, they might bring unwanted side effects. Geschwind cites examples from other clinical sciences. "I see cancer as being about a decade ahead of neuroscience," he says. "In cancer they've been effective in some cases but have also seen offtarget effects. In many ways that field is now moving towards more targeted drugs."

The large databases of autism gene candidates that are now available make the quest to explain autism more complicated than researchers had hoped. But the complexity of the condition is stimulating the expansion of approaches taken and enticing scientists to look beyond straightforward genetic explanations for autism. "We've figured out that explaining autism is not simple," says Geschwind. "But I have a pretty optimistic view. We're going to continue to make progress - and a lot of it is because of great collaboration in the field and an influx of new people tackling autism."

Sarah C. P. Williams is a freelance science writer based in Kailua, Hawaii.

1. Ritvo, E. R. et al. Am. J. Psychiatry 142, 74-77 (1985).

2. Ronald, A. et al. J. Am. Acad. Child Adol. Psy. 45, 691-699 (2006).

3. Kong, A. et al. Nature 488, 471-475 (2012).

4. Weiss, L. A. et al. Nature 461, 802-808 (2009).

5. Kerin, T. et al. Sci. Transl. Med. 4, 128ra40 (2012).

6. Luo, R. et al. Am. J. Hum. Genet. 91, 38-55 (2012)

7. Voineagu, l. et al. Nature 474, 380-384 (2011).

8. Woods, R. et al. Hum. Mol. Genet. 21, 2399-2411 (2012).

9. Iwamoto, K. et al. Genome Res. 21, 688-696 (2011).

10.Novarino, G. et al. Science doi: 10.1126/ science.1224631. 